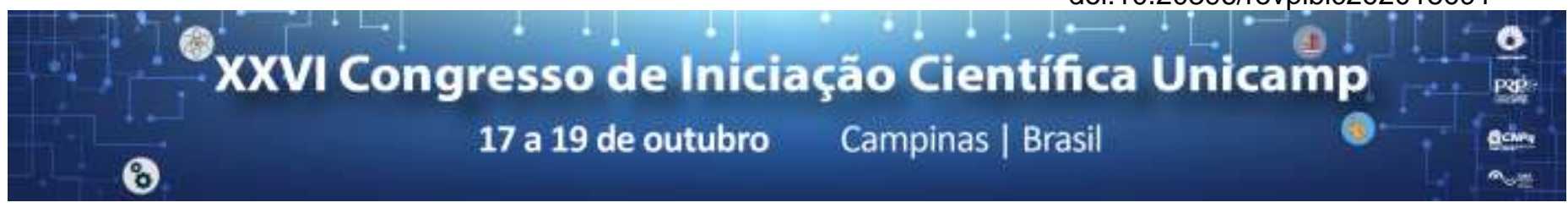

\title{
Geoquímica de água de consumo humano em duas escolas em Santarém, Pará e sua relação com a geologia regional
}

\section{Jorge L. B. Mesquita*, Anderson C. Mendes, Bernardino R. Figueiredo}

\begin{abstract}
Resumo
$\mathrm{Na}$ cidade de Santarém, Pará, grande parte do abastecimento de água provém do aquífero Alter-do-Chão (Tancredi, 1996). Foram coletadas amostras de água de duas escolas em Santarém, além de amostras de rocha para se conhecer melhor como ocorre a interação água-rocha nesta região. Foram realizadas análises de ICP-MS e Cromatografia lônica das amostras de água, e de Fluorescência de Raio X e Difração de Raio X das amostras de rocha. Os resultados indicam haver uma possível contaminação do aquífero menos profundo por fossas sépticas devido aos elevados teores de nitrato em água. Concentrações altas de alumínio em água deve ser resultado da desestabilização dos feldspatos presentes nas rochas deste aquífero.
\end{abstract}

\section{Palavras-chave:}

Hidrogeoquímica, Santarém, Alter-do-Chão

\section{Introdução}

As amostras de água que foram coletadas em duas escolas de ensino fundamental em Santarém são originárias do Aquífero Alter-do-Chão. Foram realizadas análises geoquímicas dessas águas e de amostras das rochas para que se conhecer melhor a interação águarocha para este aquífero. A escola localizada no bairro Maracanã é abastecida por um poço profundo do sistema de distribuição COSANPA $(>250 \mathrm{~m})$, enquanto a escola localizada no bairro Nova República é abastecida por um poço menos profundo $(<18 \mathrm{~m})$

\section{Resultados e Discussão}

As coletas de águas foram realizadas pela $\mathrm{Dr}$. ${ }^{\mathrm{a}}$ Marina (Meschede, 2018) nos bebedouros e torneiras da cozinha das escolas durante a estação seca (Set, Out e Nov de 2016) e chuvosa (Jan, Fev e Mar de 2017). Foram obtidos valores de $\mathrm{pH}$ e de alcalinidade, além de análises por ICP-MS e por Cromatografia lônica. Já as amostras de rochas foram coletadas durante o trabalho de campo em julho de 2017. Estas amostras foram submetidas à análises de Fluorescência de Raio $X$ e de Difração de Raio X.

Dessa forma, observou-se que a água é bicarbonatada sódica e possui valores elevados de nitrato e de alumínio (Tabela 1), seus valores de $\mathrm{pH}$ variam de 4,5 a 5,2 , caráter ácido anteriormente indicado por Tancredi (1996). Já as rochas são constituídas por arenitos podendo possuir cimentação ferruginosa, argilito, conglomerado e concreções ferruginosas. Os minerais encontrados são quartzo, caulinita e feldspato, podendo ocorrer hematita localmente. As variedades de arenito apresentam concentrações de $\mathrm{SiO}_{2}$ (variando de $97,52$ a $90,75 \%), \mathrm{Al}_{2} \mathrm{O}_{3}(2,63$ a $0,3 \%), \mathrm{Fe}_{2} \mathrm{O}_{3}(8,07$ a $0,12 \%)$.
Tabela 1. Concentração de nitrato e metais em água de consumo em duas escolas em Santarém - PA

\begin{tabular}{|c|c|c|c|c|c|c|c|c|c|c|c|c|c|}
\hline & \multicolumn{6}{|c|}{ Etalibsect } & \multicolumn{6}{|c|}{ 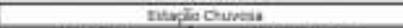 } & \multirow{4}{*}{ 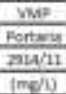 } \\
\hline & \multicolumn{3}{|c|}{ Mureand } & \multicolumn{3}{|c|}{ Rosw Reguelike } & \multicolumn{3}{|c|}{ varcand } & \multicolumn{3}{|c|}{ Nowasepibica } & \\
\hline $\operatorname{lem}$ & & & & & & & $\operatorname{imnt}$ & & & & & & \\
\hline Meses & $5 \mathrm{en}$ & ant & Nor & Set & ous & Nov & $\operatorname{Inn}$ & Fev & Mar & inn & $F=y$ & Mar & \\
\hline Na) & 832 & 0.19 & 693 & 0.06 & 6,09 & 3.61 & 6.79 & 0,19 & bed & 1,39 & 7,43 & 4.36 & 18 \\
\hline 뜨 & $17 \bar{H}$ & 171 & 2.22 & 13 & 198 & 923 & $4,4 t$ & sat & is & 7,46 & 12.6 & 7,69 & 20 \\
\hline sis & $\mathrm{s}, \mathrm{NS}$ & $a=5$ & 1.31 & Q97. & 0,37 & $2 x$ & LAE & 0,91 & 0,32 & $a, n$ & ז. $\pi$ & 0.02 & 200 \\
\hline Mg & 0.26 & 0.15 & 0.21 & ace & 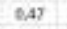 & ass & 8.27 & 0.15 & S.17 & 0.38 & a.se & 0.38 & . \\
\hline N & $0 \cos \theta$ & $\operatorname{aenz}$ & 0.28 & 2003s & 0,071 & 1,32 . & ates & $0,0<2$ & anse & b.sy & 1,35 & $a=2$ & 0,2 \\
\hline $5 i$ & 11930 & 12,3 & 12,12 & 12.45 & 12,50 & $\ln n$ & 1128 & 1457 & $24, \pi z$ & 12,13 & $22, n$ & $12,4 z$ & - \\
\hline I & 2.25 & La & 1,4 & 0.50 & 0,51 & $1, \pi$ & $13 n$ & LaA & 1.at & 1.20 & $1, \mathrm{se}$ & 1.34 & - \\
\hline 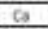 & a.t & Q.15 & 638 & 132 & $\$ .55$ & 160 & est & ats & 0.24 & 1.22 & 224 & 1,28 & $\rightarrow$ \\
\hline$F_{e}$ & 0,012 & Q006s & 6,00034 & ovos & $\log 2$. & $\cos$ & 0.0049 & coost & 0,0004 & 2000 & 6,0025 & evosi & es \\
\hline 둥 & n,Een & e.azs & 0,016 & 2000 & 8,042 & 0,0023 & 0,24 & 0,081 & $\cos 4$ & 0,01 & 0,00027 & 0,00021 & 2 \\
\hline $2 n$ & a.0on & o.013 & aed & 0,090 & c.0013 & 0,000 & 0.21 & 0.065 & 0.043 & 0,0011 & 0,00070 & a.cous & s \\
\hline pe & 0.0052 & 00017 & 0,0919 & D.0004 & 40002 & 0,0023 & 0.095 & 0.006 & Gaxas & Bav97 & 0.0693 & 0.005 & Q.01 \\
\hline
\end{tabular}

Os valores elevados de nitrato podem indicar uma possível contaminação de aquífero superficial por esgotos e fossas sépticas, o que explica os valores mais elevados na escola de Nova República. Com relação aos valores de alumínio superiores aos valores recomendados para água de consumo humano pela Portaria 2914 do Ministério da Saúde, chegou-se à conclusão de que se devem aos processos de interação água-rocha, em que a desestabilização dos feldspatos poderia explicar a presença elevada do alumínio nas águas do aquífero.

\section{Agradecimentos}

Agradeço ao $\mathrm{CNPq}$ pelo financiamento do projeto, à professora Marina Meschede pela coleta das amostras de água e pela disposição em nos guiar em Santarém, ao professor Anderson Mendes pela supervisão durante 0 trabalho de campo e aos funcionários do laboratório do IG por toda a ajuda durante as análises.

MESCHEDE, M.S.C. Implicações para a saúde dos escolares a partir do consumo de água e material particular atmosférico inalado em escolas de Santarém e Mojuí dos Campos, Pará, Amazônia. 2018. Tese (Doutorado em Saúde Pública) - Universidade Federal do Oeste do Pará, Santarém.

TANCREDI, A.C.F.N.S. Recursos hídricos subterrâneos de Santarém: Fundamentos para uso e proteção. 1996. Tese (Doutorado em Geologia) Universidade Federal do Pará, Belém. 